\title{
Dexamethasone-induced inhibition of miR-132 via methylation promotes TGF- $\beta$-driven progression of pancreatic cancer
}

\author{
ALIA ABUKIWAN ${ }^{1}$, CLIFFORD C. NWAEBURU ${ }^{1}$, NATHALIE BAUER ${ }^{1}$, ZHEFU ZHAO $^{1}$, LI LIU ${ }^{1}$, \\ JURY GLADKICH $^{1}$, WOLFGANG GROSS ${ }^{1}$, AXEL BENNER ${ }^{3}$, OLIVER STROBEL ${ }^{2}$, \\ JÖRG FELLENBERG ${ }^{4}$ and INGRID HERR ${ }^{1}$ \\ ${ }^{1}$ Molecular Oncosurgery, Section of Surgical Research; ${ }^{2}$ Department of General, Visceral and Transplant Surgery; \\ ${ }^{3}$ Department of Biostatistics, German Cancer Research Center (DKFZ); ${ }^{4}$ Orthopedics and Trauma Surgery, \\ Experimental Orthopedics, University of Heidelberg, 69120 Heidelberg, Germany
}

Received June 14, 2018; Accepted October 3, 2018

DOI: $10.3892 /$ ijo.2018.4616

\begin{abstract}
Glucocorticoids (GCs) such as dexamethasone (DEX) are administered as cancer co-treatment for palliative purposes due to their pro-apoptotic effects in lymphoid cancer and limited side effects associated with cancer growth and chemotherapy. However, there is emerging evidence that GCs induce therapy resistance in most epithelial tumors. Our recent data reveal that DEX promotes the progression of pancreatic ductal adenocarcinoma (PDA). In the present study, we examined 1 primary and 2 established PDA cell lines, and 35 PDA tissues from patients who had received $(n=14)$ or not received $(n=21)$ GCs prior to surgery. Through microRNA microarray analysis, in silico, and RT-qPCR analyses, we identified 268 microRNAs differentially expressed between DEX-treated and untreated cells. With a focus on cancer progression, we selected miR-132 and its target gene, transforming growth factor- $\beta 2$ (TGF- $\beta 2$ ), as top candidates. miR-132 mimics directly bound to the 3 ' untranslated region (3'UTR) of a TGF- $\beta 2$ luciferase construct and enhanced expression, as shown by increased luciferase activity. By contrast, DEX inhibited miR-132 expression via promoter methylation. miR-132 mimics also reduced DEX-induced clonogenicity, migration and expression of vimentin and E-cadherin in vitro and in tumor xenografts. In patients, GC intake prior to surgery enhanced global hypermethylation and expression of TGF- $\beta 2$ in tissues; expression of miR-132 was
\end{abstract}

Correspondence to: Dr Ingrid Herr, Molecular Oncosurgery, Section of Surgical Research, University of Heidelberg, Im Neuenheimer Feld 365, 69120 Heidelberg, Germany

E-mail: i.herr@uni-heidelberg.de

Abbreviations: DEX, dexamethasone; GC, glucocorticoid; JNK, c-Jun N-terminal kinase; PDA, pancreatic ductal adenocarcinoma; TGF- $\beta 2$, transforming growth factor- $\beta 2$; 3'UTR, 3' untranslated region

Key words: pancreatic cancer, glucocorticoids, epigenetics, microRNA signaling, experimental therapy detected but could not be quantified. Our results demonstrate that DEX-mediated inhibition of miR-132 is a key mediator in the progression of pancreatic cancer, and the findings provide a foundation for miRNA-based therapies.

\section{Introduction}

Pancreatic ductal adenocarcinoma (PDA) comprises more than $90 \%$ of all pancreatic cancer cases and remains one of the most deadly malignancies (1). Approximately $80 \%$ of patients already have metastases at the time of diagnosis due to the lack of early symptoms. Furthermore, potentially curative surgical resection is limited to only a few patients. Among other chemotherapeutic drugs, the deoxycytidine analog gemcitabine is used for palliative purposes to treat PDA after surgical resection (2).

Glucocorticoids (GCs) have become the cornerstone of lymphoid cancer treatment, though not all patients respond to this treatment (3). Dexamethasone (DEX), a potent synthetic GC, is often prescribed for lymphoid cancer, and is also a co-treatment for PDA and other types of epithelial tumors. Furthermore, GCs may limit the side effects of chemotherapy and cancer growth, reduce inflammation in pancreatitis, which is often associated with PDA, and inhibit tumor cachexia and pain (4). However, for epithelial tumors such as PDA, accumulating evidence indicates that GCs have anti-apoptotic effects and induce cancer progression and therapy resistance $(5,6)$. In 2003, we reported the first in vivo evidence of induction of chemotherapy resistance due to pharmacological doses of DEX in a lung and cervical cancer cell line (7), and these data have been confirmed by several experimental studies (4-6,8). Additionally, clinical studies have indicated an increased likelihood of drug resistance, disease progression and metastasis in patients with glioblastoma, oral squamous cell carcinoma and cancers of the ovary, breast, prostate or lung due to GCs (8-15). Similarly, an increased risk for skin and bladder cancer as well as non-Hodgkin lymphoma has been observed among systemic GC users $(16,17)$. Our latest data based on PDA cells demonstrate that DEX treatment mediates cancer progression and metastasis by inducing the epithelial-mesenchymal transition (EMT), and cancer stem 
cell (CSC) signaling through the activation of c-Jun N-terminal kinase (JNK)/c-Jun and transforming growth factor- $\beta$ (TGF- $\beta$ ) pathways (4).

Although GCs interfere with many signaling pathways and affect the regulation of many target genes, the entire spectrum of their molecular, cell type-specific activity is still not completely understood. MicroRNAs (miRNAs) are potential key players because these highly conserved, small, 19-25-nucleotide-long, single-stranded, endogenous, non-coding RNAs act as cell context-dependent transcriptional regulators (18-20). miRNAs bind to the 3'-untranslated region (3'UTR) of a target messenger RNA (mRNA) and induce translational suppression or mRNA degradation. A growing body of evidence indicates that GCs modulate the expression of miRNAs; for example, cortisol treatment of HeLa cells was shown to mediate the downregulation of miR-145, and thereby the invasion and therapy resistance (21).

Nonetheless, the involvement of miRNA signaling in GC-induced CSC and EMT signaling pathways in PDA has not yet been studied. Through miRNA microarray analysis, bioinformatics evaluation and RT-qPCR, we detected the significant deregulation of several miRNAs in PDA cells after treatment with DEX, and we selected miR-132 as the most important candidate. Herein, we demonstrate that DEX regulates the expression of miR-132 through promoter methylation. Consequently, miR-132 mimics transfected into cells activate TGF- $\beta 2$ expression via directly binding to its $3^{\prime} \mathrm{UTR}$, which in turn causes enhanced clonogenicity, migration and EMT-associated expression.

\section{Materials and methods}

Human primary and established cell lines. AsPC-1 and PANC-1 pancreatic cancer cell lines were obtained from the American Type Culture Collection (Manassas, VA, USA). The established cell lines were recently authenticated by a commercial service (Multiplexion GmbH, Heidelberg, Germany). The human primary pancreatic cancer cell line ASAN-PaCa, which has been described previously, was kindly provided by Dr N. Giese (22). To maintain the authenticity of the cell lines, we prepared frozen stocks from the initial stocks, and a new thawed stock was used every three months for experiments. Monthly testing ensured mycoplasma-negative cultures. Cells were cultured under standard conditions in DMEM (PAA Laboratories GmbH; GE Healthcare Life Sciences, Little Chalfont, UK) supplemented with 10\% heat-inactivated fetal calf serum (FCS; Sigma-Aldrich; Merck KGaA, Darmstadt, Germany) and $25 \mathrm{mmol} / \mathrm{l}$ HEPES (PAA).

Patient tissues. Tissue specimens were obtained from patients who had undergone surgery at the Department of General, Visceral and Transplant Surgery, University of Heidelberg, from January 2014 to December 2016. The Ethics Committee of the University of Heidelberg approved the study after receiving written informed consent from the patients. Clinical diagnoses were established by conventional clinical and histological criteria. Surgical resection was performed as indicated by the principles and practice of oncological therapy.

Reagents and treatment of cells. Stock solutions of DEX ( $25 \mathrm{mM}, \geq 98 \%$ pure), Sigma-Aldrich; Merck KGaA) were prepared in ethanol. A solution of 5'AZA-2'-deoxycytidine was freshly diluted with the cell culture medium to prepare a $10 \mu \mathrm{M}$ stock solution (23).

miRNA microarray profiling and analysis. Total RNA was extracted with the use of a Qiagen miRNeasy Mini Isolation Kit (Qiagen, Hilden, Germany). Agilent Human miRNA Microarray (Release 19.0) covering 2006 human microRNAs was used for microRNA profiling. The raw array data were analyzed by the Linear Regression Model for Microarrays (LIMMA) software version 3.24.15. The Benjamini and Hochberg (BH) algorithm was used to correct for multiple testing and false discovery rates (FDRs). Gene Ontology analysis was used to detect associations between the identified set of miRNA candidates and the associated specific biological processes and molecular functions. The microarray data were uploaded to Array Express (https://www. ebi.ac.uk/arrayexpress/help/accession_codes.html) under the accession number E-MTAB-4718.

In silico analysis and target prediction. Gene Ontology (www.geneontology.org) was used to analyze the miRNA array data for identification of a set of significantly and differentially regulated miRNAs with similar functions. The 100 most significantly deregulated miRNAs after $96 \mathrm{~h}$ of DEX treatment were uploaded, and the keywords EMT, Wnt and SMAD were entered. The commercially available Ingenuity Pathway Analysis (IPA) database (Qiagen) was used for identifying targets of the top differentially regulated miRNAs. In addition, the databases miRanda (http://www.microrna.org) (24), TargetScan (http://www.targetscan.org) (25), miRwalk (http://mirwalk. uni-hd.de/) (26) and PicTar (http://www.pictar.org) http://www. pictar.org (27) were used for miRNA target gene prediction. Potential candidates with mirSVR scores $<-0.1$ were considered. We then chose the most common predictions of the different databases; the results from miRwalk and IPA were preferred as their data were the most up-to-date. The binding site of miR-132 in the 3'UTR of TGF- $\beta 2$ was identified with TargetScan.

TaqMan miR real-time $q P C R$. cDNA was synthesized from 500 ng total RNA using TaqMan ${ }^{\circledR}$ Reverse Transcription Reagents (Thermo Fisher Scientific, Inc.) according to the manufacturer's instructions, and $1 \mu 1 \mathrm{cDNA}$ was used for quantitative PCR. Quantitative PCR was performed using a TaqMan Assay with specific primers. RNU6 served as an internal control for hsa-miR-132-3p expression, and GAPDH was the internal control for vimentin and E-cadherin expression (Thermo Fisher Scientific, Inc.). The PCR was performed using a StepOne Real-Time PCR System (Thermo Fisher Scientific, Inc.), and changes in relative concentration were calculated with the second derivative maximum method $2^{-\Delta \Delta \mathrm{Cq}}$ (28). The $\Delta \mathrm{CT}$ value was calculated by subtracting the $\mathrm{CT}$ of the housekeeping gene from the $\mathrm{CT}$ of the gene of interest $[\Delta \mathrm{CT}=\mathrm{Ct}$ (gene of interest) - Ct (housekeeping gene)]. Fold change data were generated using the equation $\Delta \Delta \mathrm{CT}=\Delta \mathrm{CT}$ (treated sample) $-\Delta \mathrm{CT}$ (untreated sample).

Global DNA methylation analysis. An ELISA-based MethylFlash Methylated DNA 5-mC Quantification Kit (Colorimetric; Epigentek, distributed by BioCat, Heidelberg, Germany) was used for quantification of total 5-methylcytosine 
(5-mC). This assay detects the methylated fraction of DNA with antibodies followed by quantification through an ELISA-like reaction using the absorbance at $450 \mathrm{~nm}$ measured by a microplate spectrophotometer. After genomic DNA was prepared by the DNeasy ${ }^{\circledR}$ blood and tissue kit (Qiagen), 100 ng DNA was bound to each well of the assay plates in biological and technical duplicates $(n=4)$. After the plates were washed, the capture antibody was added; after another wash, the detection antibody and an enhancer solution were added. A color-developing solution was then added, and absorbance was measured at $450 \mathrm{~nm}$. A standard curve was generated for absolute 5-mC quantification.

Methylation-specific PCR. A methylation-specific PCR analysis of the miR-132 promoter CpG island located on chromosome 17, between base pairs 497 and 545 upstream of the transcriptional start site, was performed as described (29). Genomic DNA was extracted from PDA cells using a QIAamp DNA Mini Kit (Qiagen), and a 100-ng sample of DNA was modified with bisulfite using EZ DNA Methylation ${ }^{\mathrm{TM}} \mathrm{Kit}$ following the manufacturer's instructions (Zymo Research, Irvine, CA, USA). PCR was performed with $20 \mathrm{ng}$ bisulfite-modified DNA using the HotStar Polymerase Kit (Qiagen). The PCR primers were as follows: methylated miR-132 forward, 5'-TTTTTTGGGATATT TTTGACGTTAC-3', methylated miR-132 reverse, 5'-CCGACT AAAAACTCTACTACTCCG-3', amplifying a 122-bp fragment; unmethylated miR-132 forward, 5'-TTTTTGGGATATT TTTGATGTTATG-3', unmethylated miR-132 reverse, 5'-CCA ACTAAAAACTCTACTACTCCAC-3', amplifying a 121-bp fragment. PCR settings were $95^{\circ} \mathrm{C}$ for $5 \mathrm{~min}$, followed by 40 cycles of $94^{\circ} \mathrm{C}$ for $30 \mathrm{sec}, 62^{\circ} \mathrm{C}$ for $30 \mathrm{sec}$, and $72^{\circ} \mathrm{C}$ for $60 \mathrm{sec}$, with a final extension step at $72^{\circ} \mathrm{C}$ for $7 \mathrm{~min}$.

Site-directed mutagenesis of the TGF- $\beta 2$ 3'UTR miR-132 binding site. A Renilla luciferase reporter construct expressing the wild-type (wt) 3'UTR TGF- $\beta 2$ was purchased from BioCat. The complete putative 3'UTR binding region for miR-132 was exchanged using QuikChange Site-Directed Mutagenesis Kit to create a mutated (mt) site (Agilent Technologies, Waldbronn, Germany). The following primer sequences were created with the QuikChange Primer Design Program (Agilent Technologies) and ordered from Eurofins GATC Biotech GmbH (Konstanz, Germany): TGF- $\beta$-M1-3'UTR forward, 5'-GCC TAA GGA AGC TTC TTG TAA GGT CCA AAA ACT AAA ATC TGA CAT AAT AAA AGA AAA CTT TCA GTC AGA ATA AGT CTG TAA G-3'; TGF- $32-M 1-3$ 'UTR reverse, 5'-CTT ACA GAC TTA TTC TGA CTG AAA GTT TCT TTT ATT ATG TCA GAT TTT AGT TTT GGA CCT TAC AAG AAG CTT CCT TAG GC-3'. The sequences of the generated wt and $\mathrm{mt}$ miR-132 3'UTR plasmids were confirmed by sequencing (Eurofins GATC Biotech $\mathrm{GmbH}$ ).

miRNA transfection. MirVana ${ }^{\mathrm{TM}}$ mimics [miR-132-3p and non-coding miRNA (miR-NC)] at $50 \mathrm{nM}$ each were transfected into cells using Lipofectamine 2000 (both from Thermo Fisher Scientific, Inc.) using the reverse transfection method described in the manufacturer's instructions.

Dual-Luciferase ${ }^{\circledR}$ reporter assay. Cells were seeded at a density of $1 \times 10^{4}$ cells per well into a 96-well plate and co-transfected with $50 \mathrm{nM}$ miR mimics, $25 \mathrm{ng} /$ well Firefly luciferase plasmid and $50 \mathrm{ng} /$ well Renilla luciferase reporter construct expressing TGF- $\beta 2$ 3'UTR (BioCat). The cells were lysed in Passive Lysis Buffer of the Dual-Luciferase ${ }^{\circledR}$ Assay System (Promega Corporation, Mannheim, Germany) at $48 \mathrm{~h}$ post-transfection. Renilla and Firefly luciferase activities were measured using the FLUOstar OPTIMA instrument (BMG Labtech GmbH, Ortenberg, Germany).

Wound-healing assay. Cells were harvested $24 \mathrm{~h}$ after transfection and at $12 \mathrm{~h}$ after DEX treatment, resuspended in DMEM supplemented with $10 \%$ FCS and plated at a density of $5 \times 10^{5}$ cells $/ \mathrm{ml}$ in ready-to-use culture-inserts in a $\mu$-Dish (ibdiTreat, item \#80241; ibidi GmbH, Martinsried, Germany). At $100 \%$ cell confluence, the inserts were removed, leaving a $500-\mu \mathrm{m}$ gap in each dish; fresh medium was added. After 24 and 48 h, images were taken with a Nikon Eclipse TS 100-F inverted microscope equipped with a camera. Images (5 per treatment condition) were obtained, and analysis was performed with the WimScratch Quantitative Wound-Healing Image Analysis Software version 1 (item \#30002; ibidi GmbH).

Western blot analysis. Western blot analysis was performed as previously described (30). Rabbit monoclonal antibodies against TGF- 32 (\#710276; ABfinity ${ }^{\mathrm{TM}}$; Thermo Fisher Scientific, Inc., Waltham, MA USA), E-cadherin (\#3195-S; Cell Signaling Technology, Inc., Danvers, MA, USA), and vimentin (\#EPR3255; Abcam, Cambridge, UK) and a mouse monoclonal antibody against $\beta$-actin (\#A1978; Sigma-Aldrich; Merck KGaA) were used. All primary antibodies were diluted 1:1,000 and secondary antibodies 1:5,000; the incubations were all performed at room temperature.

Colony-forming assay. AsPC-1, PANC-1 and ASAN-PaCa cells were transfected with $50 \mathrm{nM}$ miR-132 mimics or a negative miR control (NC). At $8 \mathrm{~h}$ later, the cells were treated with $1 \mu \mathrm{M} \mathrm{DEX}$ in the presence or absence of miR-132. After $48 \mathrm{~h}$, the cells were resuspended in DMEM supplemented with $10 \%$ FCS and plated at a density of 400 (AsPC-1 and PANC-1) or 1,000 cells/well (ASAN-PaCa) in 6-well tissue culture plates. The cultures were maintained under standard culture conditions for 14 days, followed by an evaluation of those fixed and Coomassie-stained colonies consisting of $\geq 50$ cells. The plating efficiency was calculated as a percentage: (number of colonies/number of seeded cells) x100, as previously described (30).

Immunohistochemistry and immunofluorescence staining. Immunofluorescence staining was performed on $6-\mu$ m-thick frozen or paraffin-embedded tissue sections, as previously described (31). The following antibodies were used: Mouse monoclonal antibodies against TGF- 32 (\#ab36495), vimentin (\#ab8059) and 5-methylcytosine (\#ab10805) (all from Abcam), and rabbit monoclonal antibodies against E-cadherin $(\# 3195 \mathrm{~s}$; Cell Signaling Technology, Inc.) and Ki-67 (\#ab92742; Abcam). Primary antibodies were diluted 1:50 and secondary antibodies 1:400; the incubations were all performed at room temperature. Signals were detected with a Leica DMRB fluorescence microscope (Leica Microsystems Ltd., Milton Keynes, UK). Images of representative fields were captured using a SPOTTM FLEX 15.2 64-Mp shifting pixel digital color camera and analyzed with SPOT Basic/Advanced 4.6 
software (both from Diagnostic Instruments, Sterling Heights, Michigan, USA).

In situ hybridization of miR-132. Detection of miR-132 expression in tissue sections was achieved using miRCURY LNA ${ }^{\text {TM }}$ microRNA Detection Kit (Exiqon, Vedbaek, Denmark) as described (32). Staining was performed on formalin-fixed, paraffin-embedded patient tissues. Briefly, sections were dewaxed in Roti-Histol (Carl Roth GmbH \& Co. KG, Karlsruhe, Germany), rehydrated in 2-propanol, treated with proteinase $\mathrm{K}$ $(15 \mu \mathrm{g} / \mathrm{ml})$ and air-dried. Hybridization was performed for $2 \mathrm{~h}$ at $58^{\circ} \mathrm{C}$ using a miR-132-specific, digoxigenin-labeled locked nucleic acid (LNA) detection probe and a scrambled miR as a negative control. After stringent washes, the bound LNA probes were detected with an alkaline phosphatase-coupled digoxigenin antibody (Sigma-Aldrich; Merck KGaA) and NBT/BCIP (Thermo Fisher Scientific, Inc.) as the substrate. The sections were mounted using Roti-Mount FluorCare (Carl Roth GmbH\& Co. KG) containing 4',6-diamidino-2-phenylindole (DAPI) as a counterstain.

Tumor xenotransplantation into fertilized chick eggs and in ovo treatment. ASAN-PaCa cells were transfected with $50 \mathrm{nM}$ mirVana $^{\mathrm{TM}}$ mimics of hsa-miR-132 or miR-NC using the Lipofectamine $2000^{\circledR}$ reagent (both from Thermo Fisher Scientific, Inc.). At $8 \mathrm{~h}$ later, the cells were treated with DEX or left untreated. At $48 \mathrm{~h}$ later, the cells were transplanted to the chorioallantoic membrane (CAM) of fertilized chicken eggs on day 9 of embryonic development $(n=25)$. On developmental day $14,50 \mu 1 \mathrm{miR}$-Lipofectamine mixture containing $50 \mathrm{nM}$ hsa-miR-132 mimics or saline as a control were injected into the CAM vessels supplying the tumor xenografts. Fertilized eggs from genetically identical hybrid Lohman Brown (LB) chickens were obtained from a local ecological hatchery (Geflügelzucht Hockenberger, Eppingen, Germany), and tumor xenotransplantation, treatment, and evaluations of tumor take, tumor growth and metastasis were performed as described recently (33).

Statistical analysis. Quantitative data are presented as the mean \pm SD of experiments performed in triplicate. The data were analyzed using Student's t-test for statistical significance. The data were evaluated by the Mann-Whitney test and by the Kruskal-Wallis test followed by Mann-Whitney and Bonferroni-Holm tests. The in vivo tumor growth data were evaluated by the Kruskal-Wallis test followed by the Mann-Whitney and Bonferroni-Holm tests. Statistical significance was considered to be indicated by values of $\mathrm{P}<0.05$.

\section{Results}

Dexamethasone regulates miRNA expression. To evaluate potential GC-regulated miRNAs, we treated the established PDA cell line AsPC-1 with DEX for $0.5,24$ or $96 \mathrm{~h}$, or left the cells untreated as a control. Total RNA was isolated and examined by Agilent Human miRNA Microarray analysis (Release 19.0). Based on bioinformatics evaluation, 268 miRNAs were significantly $(\mathrm{P}<0.05)$ differentially regulated at $96 \mathrm{~h}$, more than at any other time-point. Among these 268 miRNAs, 112 were upregulated and 85 downregulated. The 24 top deregulated miRNAs with the lowest standard
Table I. Prediction of miRNA candidates by in silico gene ontology analysis.

\begin{tabular}{|c|c|c|c|}
\hline miRNA & Confidence & Gene & Key pathways \\
\hline $132-3 p$ & High & SMAD2 & TGF $\beta$, EMT \\
\hline $132-3 p$ & High & SMAD5 & TGF $\beta$, EMT \\
\hline $132-3 p$ & High & GSK3 $\beta$ & TGF $\beta$, Wnt, EMT \\
\hline $132-3 p^{a}$ & Moderate $^{a}$ & TGF- $\beta 2^{\mathrm{a}}$ & TGF $\beta, \mathrm{EMT}^{\mathrm{a}}$ \\
\hline $132-3 p$ & High & KRAS & PDA, EMT \\
\hline $132-3 p$ & High & MAPK1 & MAPK, EMT \\
\hline $132-3 p$ & High & FOXO3 & GCs \\
\hline 1275 & Moderate & SMAD3 & SMAD, EMT \\
\hline 1275 & Moderate & SMAD9 & SMAD, EMT \\
\hline 210 & High & INHBB & TGF $\beta$, EMT \\
\hline 210 & High & ACVR1B & Wnt, EMT \\
\hline 210 & Moderate & SOX15 & Wnt, EMT \\
\hline 1246 & High & GSK3 $\beta$ & TGF $\beta$, Wnt, EMT \\
\hline 1246 & High & $\mathrm{CDH} 2$ & Cell-cell junctions \\
\hline 1246 & High & AXIN2 & Wnt, EMT \\
\hline $1260 \mathrm{~b}$ & High & $\mathrm{Bcl} 2$ & Apoptosis \\
\hline $1260 \mathrm{~b}$ & High & Akt2 & MAPK, PI3K \\
\hline $378 \mathrm{i}$ & High & BMP2 & TGF $\beta$, EMT \\
\hline $378 \mathrm{i}$ & High & MAPK1/9 & MAPKs \\
\hline $99 a-5 p$ & High & BMPR2 & Wnt, TGF $\beta$ \\
\hline
\end{tabular}

aTop candidate. The keywords 'glucocorticoids', 'epithelial-mesenchymal-transition', 'apoptosis', 'Wnt' and 'Smad' were used for in silico prediction analysis. A confidence of 'high' or 'moderate' was assigned based on the level of evidence provided by miRNAseq experiments, as described by the online database miRBase.

deviations are shown as a heatmap in Fig. 1A. We performed Gene Ontology analysis to elucidate which pathways are regulated by the most significantly regulated miRNAs and used keywords 'EMT', 'DEX', 'Wnt' and 'Smad' to determine miRNAs associated with DEX-induced EMT. In total, 7 of the 100 deregulated miRNAs were found to share all of these pathways, as shown in a Venn diagram (Fig. 1B; Table I). Finally, TargetScan, miRanda, miRwalk and Ingenuity Pathway Analysis (IPA) tools were applied, resulting in the selection of miR-132-3p with its predicted target gene TGF- $\beta 2$ as the most relevant miRNA candidate. Via RT-qPCR we confirmed that DEX induced differential regulation of miR-132-3p, the expression of which was upregulated at $0.5 \mathrm{~h}$ after DEX treatment but downregulated at $24 \mathrm{~h}$ and completely inhibited at 96 h (Fig. 1C).

DEXinhibitsmiR-132expressionbypromoterhypermethylation. We hypothesized that promoter hypermethylation may play a role in the observed DEX-induced downregulation of miR-132. Because cytosines in $\mathrm{CpG}$ dinucleotides are methylated to form $5-\mathrm{mC}$, we searched for the presence of $\mathrm{CpG}$ islands in the miR-132 promoter using the UCSC genome browser (https://genome.ucsc.edu) and found several upstream of the miR-132 transcription start site (data not shown). To evaluate the ability of DEX to induce DNA methylation, we quantified the amount of total 5-mC using a highly sensitive, colorimetric 

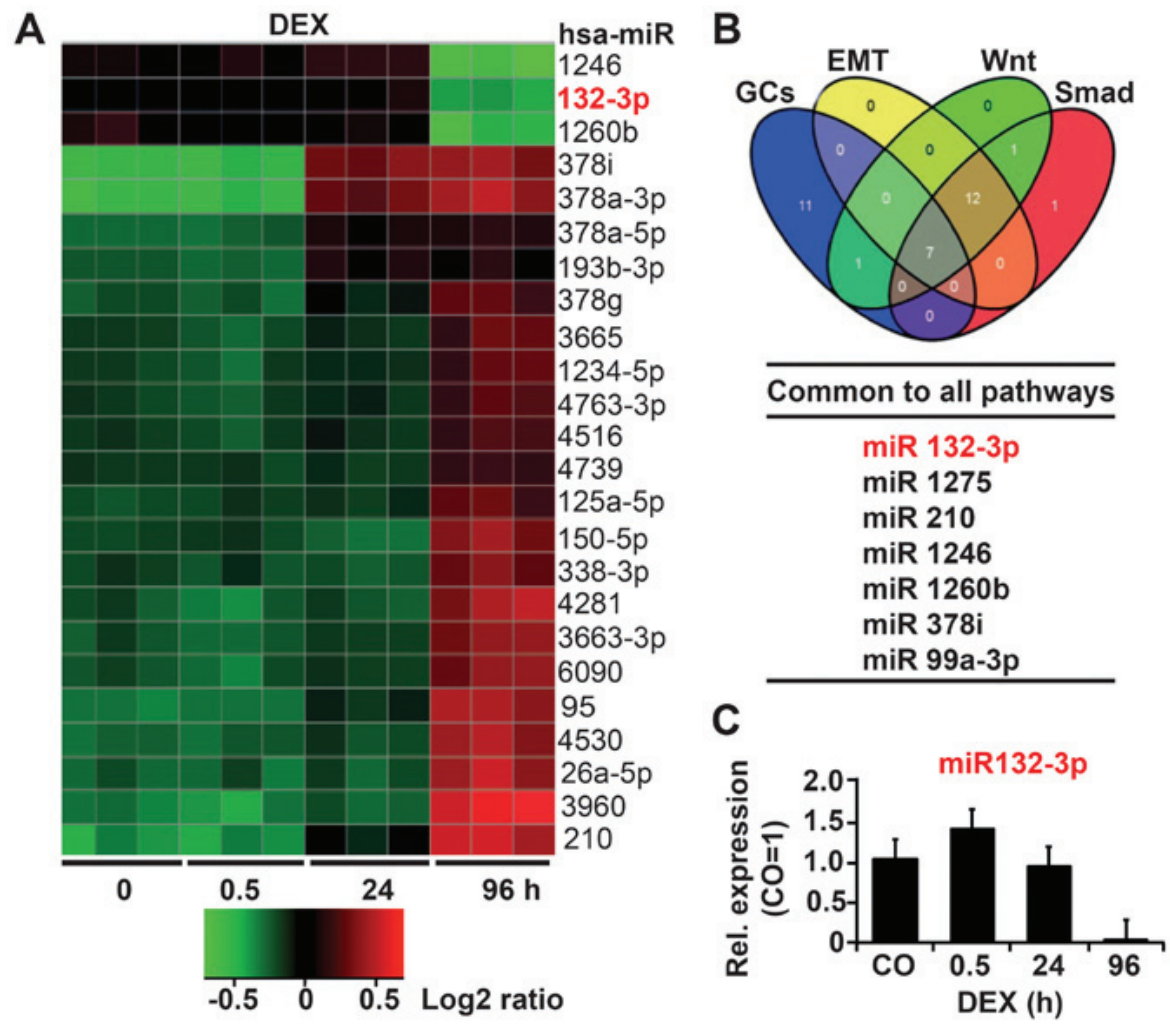

Figure 1. DEX downregulates miR-132. (A) AsPC-1 cells were treated with $1 \mu \mathrm{M}$ DEX or left as CO. Total RNA was extracted at 30 min, 24 and 96 h and analyzed by Agilent miRNA Microarray (Release 19.0). The heatmap includes the top 24 significantly differentially upregulated and downregulated miRNAs The red color indicates high expression, and the green color indicates low expression. (B) A Venn diagram was created based on the top three candidates and the results of in silico analysis with the keywords glucocorticoids, EMT, Wnt and Smad using different bioinformatics algorithms. (C) AsPC-1 cells were treated with DEX as indicated or left untreated as a CO, followed by the isolation of total RNA and RT-qPCR analysis with primers specific for miR-132-3p. Expression levels were normalized to that of RNU6B. The mean fold change in the CO cells was set to 1; the expression levels in treated cells were relative to that of the CO. DEX, dexamethasone; miRNA, microRNA; EMT, epithelial mesenchymal transition; CO, control/untreated.

ELISA-based assay. PDA cells were treated or not with DEX, followed by isolation of genomic DNA after $96 \mathrm{~h}$. After DNA capture and detection with specific antibodies, signal enhancement and color development, absorbance at $450 \mathrm{~nm}$ was measured using a microplate spectrophotometer. With the 5-mC level in the controls set to 1, DEX significantly enhanced 5-mC levels to 2 in AsPC-1 and PANC-1 cells, and to 2.5 in ASAN-PaCa cells (Fig. 2A). The presence of $5-\mathrm{mC}$ was also detected by IHC in the tissues of patients with PDA (Fig. 2B and C; Table II) who had taken GCs prior to surgery via inhalation $(n=8)$ or oral $(n=6)$ methods, and in the tissues of patients with PDA who had not taken GCs $(n=18)$. A greater level of methylation was present in tissues from patients who were treated with GCs relative to in tissues from patients who did not receive GC therapy, with the highest level appearing with oral intake, confirming the in vitro results.

To examine whether DEX methylates the miR-132 promoter, we performed methylation-specific PCR using primers for the CpG-rich portion upstream of the miR-132 promoter located at 497-540 bp. Cells were treated with DEX or left untreated, followed by total DNA isolation $96 \mathrm{~h}$ later. The extracted DNA was treated with bisulfite to convert the cytokine residues to uracil, leaving 5-methylcytosine residues unaffected. For the PCR reaction, we used a specific methylation primer pair that selectively amplifies the $\mathrm{CpG}$-rich region containing methylated cytosine residues. In parallel, an unmethylated primer pair was used to amplify this region only if the non-methylated cytokine residues were reverted to uracil residues by bisulfite. The PCR products were separated by agarose gel electrophoresis, and representative results are shown (Fig. 2D). Although untreated AsPC-1 and PANC-1 cells yielded a band when using the unmethylated primer pair, cells treated with DEX yielded a strong band when using the methylated primer pair, which was suggestive of DEX-induced hypermethylation of the miR-132 promoter. These data indicate that methylation of the miR-132 promoter plays a role in decreased miR-132 expression.

miR-132 targets TGF- $\beta 2$. To gain insight into the molecular mechanisms by which miR-132 regulates TGF- $\beta 2$ expression, we examined whether miR-132 directly binds to the TGF- $\beta 2$ 3'UTR region (Fig. 3A), which contains a putative binding site for miR-132, as identified by TargetScan. Based on a wt pLightSwitch $^{\mathrm{TM}}$ - TGF- $\beta 2-3$ 'UTR luciferase vector, we mutated the target site of the TGF- $\beta 2-3$ 'UTR region to create the $\mathrm{mt}$ pLightSwitch $^{\text {TM }}$-TGF- $32-3$ 'UTR luciferase plasmid. AsPC-1, PANC-1 and ASAN-PaCa cells were transfected with the wt and $\mathrm{mt}$ pLightSwitch- TGF- $\beta 2-3$ 'UTR constructs in the presence of miR-132 mimics. At $48 \mathrm{~h}$ after transfection, a luciferase reaction was performed, and luciferase activity was quantified using a luminescence microplate reader. We found that in all cell lines, miR-132 markedly reduced the luciferase reporter activity of the wt- but not the mt-TGF- 32 3'UTR construct (Fig. 3B). Furthermore, miR-132 significantly inhibited expression of the 
A

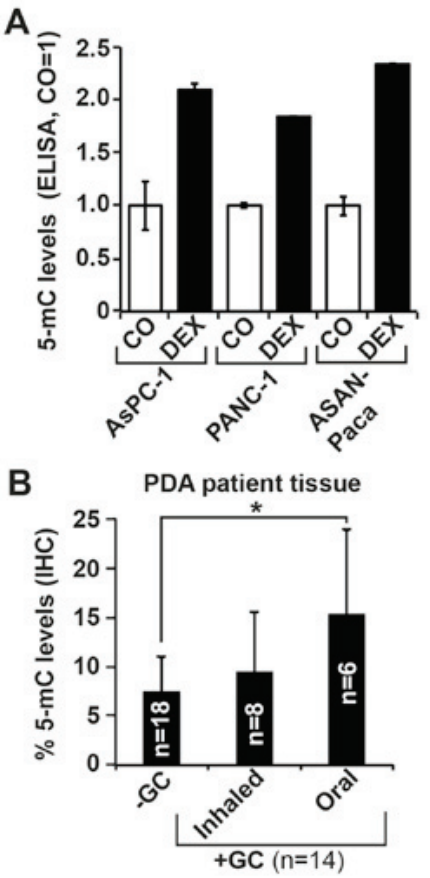

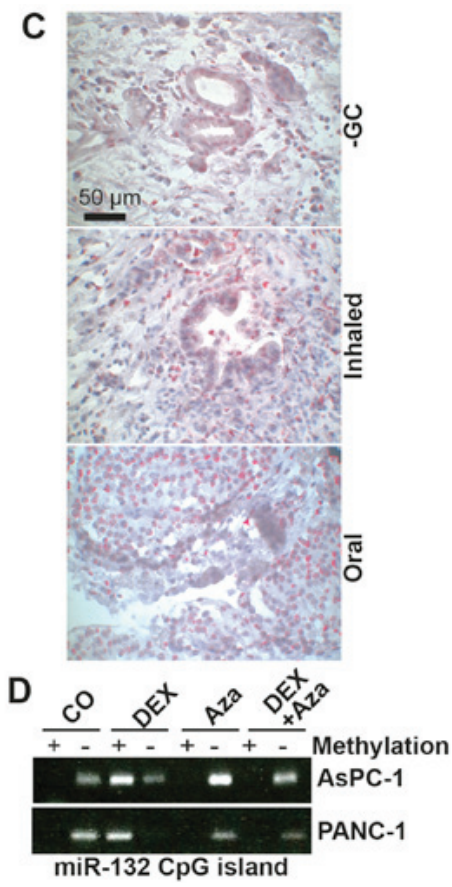

Figure 2. DEX inhibits miR-132 expression via promoter hypermethylation. (A) AsPC-1, PANC-1 and ASAN-PaCa cells were treated with $1 \mu \mathrm{M}$ DEX or left untreated (CO) for $96 \mathrm{~h}$. Genomic DNA was extracted, and 5-mC levels were detected using a 5-mC DNA Elisa kit. (B) Representative paraffin sections from the tissues of patients with documented pre-operative inhaled or oral intake of GCs (+GC, $n=14$; inhaled $n=8$, oral $n=6)$ or without GC treatment $(-\mathrm{GC}$, $\mathrm{n}=18$ ) were evaluated by IHC to detect expression of 5-mC. The number of positive cells was quantified in 10 visual fields for each group at x400 magnification. (C) Representative staining of tissues from patients in each group is shown. The scale indicates $50 \mu \mathrm{m}$. (D) AsPC-1 and PANC-1 cells were left untreated or treated with $1 \mu \mathrm{M}$ DEX, $10 \mu \mathrm{M}$ of the demethylating agent Aza, or both. At $72 \mathrm{~h}$ later, genomic DNA was extracted followed by bisulfite conversion of non-methylated cytokine residues to uracil. PCR was performed with two primer pairs targeting the CpG island located at 497-540 bp of the miR-132 promoter. The first primer pair detected a band $120 \mathrm{bp}$ in size in the presence of methylcytosine residues (+), whereas the second primer pair amplified this region only in the presence of uracil residues (-). The amplified DNA was separated by agarose gel electrophoresis, and the bands were visualized by ethidium bromide staining, UV-transillumination and photography. The results from parts A and B are shown as the means $\pm \mathrm{SD}$. "P<0.05. DEX, dexamethasone; miR, microRNA; CO, control/untreated; Aza, 5'-AZA-2-deoxycytidine; GC, glucocorticoids.

A

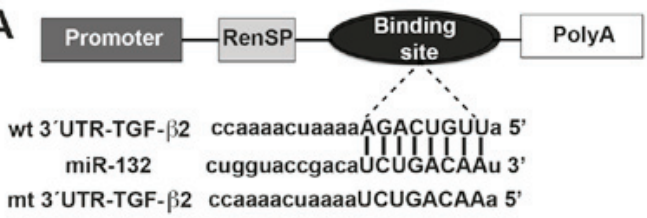

B

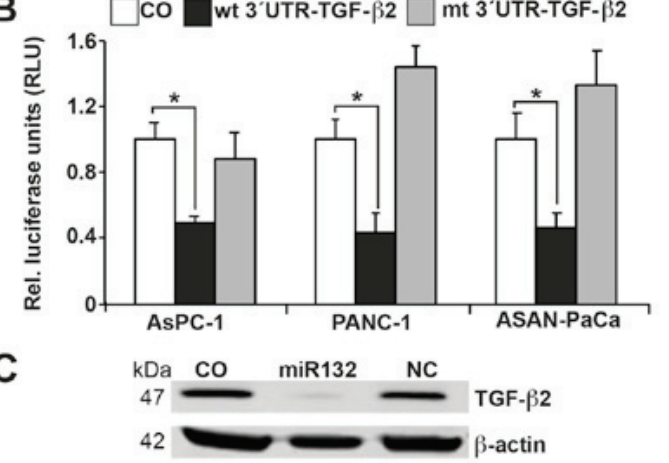

D
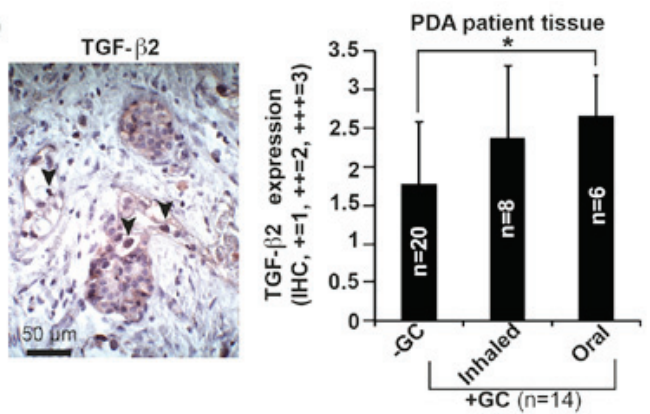

E

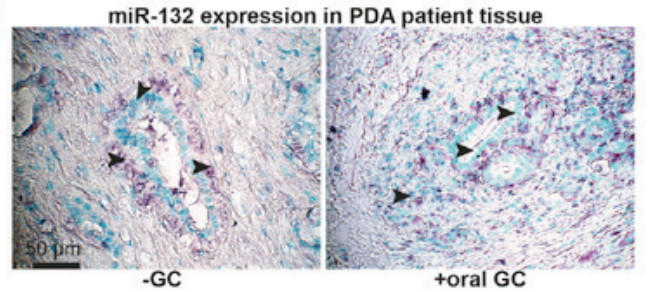

Figure 3. miR-132 binds to the 3'UTR of TGF- $\beta 2$ to inhibit its expression. (A) Schematic of the miR-132 binding site in the TGF- $\beta 2$ 3'UTR at position 746-753 and its sequence homology to miR-132. The mutant version of the TGF- $\beta 2$ 3'UTR is shown. (B) The wt and mt TGF- $\beta 2$ 3'UTRs were cloned into a pLightSwitch Renilla plasmid and transfected into AsPC-1, PANC-1 and ASAN-PaCa cells in the presence or absence of $50 \mathrm{nM}$ miR-132 mimics. Negative mimics served as a control. Co-transfection with Firefly luciferase $(0.25 \mathrm{ng} / \mu \mathrm{l})$ served as a normalization control. At $48 \mathrm{~h}$ after transfection, the expression of Renilla and Firefly luciferases was detected using a FLUOstar Omega microplate reader. Renilla luciferase activities were normalized to Firefly luciferase activities. (C) PANC-1 cells were transfected with miR-132 or non-coding miRNA (NC), or mock-treated without miRNA (CO). Proteins were harvested $48 \mathrm{~h}$ later and analyzed by western blotting. $\beta$-actin served as the normalization control. (D) Representative paraffin-embedded PDA tissue sections from patients with documented pre-operative intake of inhaled $(n=8)$ or oral $(n=6)$ GCs $(+G C, n=14)$ and from those without GC intake $(-G C, n=20)$ were evaluated by IHC to detect the expression of TGF- $\beta 2$. A semi-quantitative scoring system was used to evaluate expression levels based on visual determination of the percentage of positive cells. The sections were analyzed at $\times 400$ magnification, and representative images are shown. (E) In situ hybridization of miR-132 expression in patient tissues. The arrows indicate positive cells. Representative results for part B are shown as the means $\pm \mathrm{SD}$. "P<0.05. UTR, untranslated region; wt, wild-type; mt, mutant/mutated; miR, microRNA; CO, control/untreated; GC, glucocorticoids. 
Table II. PDA patient tissues: Expression levels and medication.

\begin{tabular}{|c|c|c|c|c|c|}
\hline $\begin{array}{l}\text { Patient } \\
\text { no. }\end{array}$ & GC & Intake & Dose/d & $5-\mathrm{mC}(\%)$ & TGF- $\beta 2$ \\
\hline 1 & - & - & - & I & ++ \\
\hline 2 & - & - & - & / & +++ \\
\hline 3 & - & - & - & 3.4 & + \\
\hline 4 & - & - & - & 11.3 & ++ \\
\hline 5 & - & - & - & 5.2 & ++ \\
\hline 6 & - & - & - & 8.3 & + \\
\hline 7 & - & - & - & 3.7 & +++ \\
\hline 8 & - & - & - & 9.8 & + \\
\hline 9 & - & - & - & 1 & ++ \\
\hline 10 & - & - & - & 6.4 & + \\
\hline 11 & - & - & - & 6.1 & + \\
\hline 12 & - & - & - & 6.88 & + \\
\hline 13 & - & - & - & 8.75 & ++ \\
\hline 14 & - & - & - & 18.45 & +++ \\
\hline 15 & - & - & - & 8.61 & + \\
\hline 16 & - & - & - & 8.34 & ++ \\
\hline 17 & - & - & - & 6.54 & ++ \\
\hline 18 & - & - & - & 3.92 & +++ \\
\hline 19 & - & - & - & 8.51 & - \\
\hline 20 & - & - & - & 5.41 & - \\
\hline \multirow[t]{2}{*}{21} & - & - & - & 5.44 & + \\
\hline & & & & 7.50 & ++ \\
\hline \multirow[t]{2}{*}{22} & Beclometasonedipropionate & Inhalation & $100 \mu \mathrm{g}$ & & \\
\hline & Fluticasonefuroate & Inhalation & $27.5 \mu \mathrm{g}$ & 5.81 & ++ \\
\hline 23 & Budesonide & Inhalation & $3 \mathrm{mg}$ & 14.95 & +++ \\
\hline \multirow[t]{2}{*}{24} & Beclometasonedipropionate & Inhalation & $100 \mu \mathrm{g}$ & & \\
\hline & Fluticasonefuroate & Inhalation & $27.5 \mu \mathrm{g}$ & 12.26 & ++ \\
\hline 25 & Fluticasone & Inhalation & $250 \mu \mathrm{g}$ & 20.43 & ++ \\
\hline 26 & Budesonide & Inhalation & $200 \mu \mathrm{g}$ & 8.46 & ++ \\
\hline 27 & Fluticasonefuroate & Inhalation & $100 \mu \mathrm{g}$ & 4.8 & +++ \\
\hline 28 & Budesonide & Inhalation & $400 \mu \mathrm{g}$ & 2.37 & + \\
\hline \multirow[t]{2}{*}{29} & Beclometasonepropionate & Inhalation & $100 \mu \mathrm{g}$ & 7.44 & + \\
\hline & & & & 9.57 & ++ \\
\hline 30 & Prednisone & Oral & $40 \mathrm{mg}$ & 9.06 & ++ \\
\hline 31 & Prednisolone & Oral & $5 \mathrm{mg}$ & 15.43 & +++ \\
\hline 32 & Prednisolone & Oral & $3 \mathrm{mg}$ & 16.24 & +++ \\
\hline 33 & Prednisolone & Oral & $6 \mathrm{mg}$ & 10.07 & ++ \\
\hline 34 & Prednisolone & Oral & $50 \mathrm{mg}$ & 31.49 & +++ \\
\hline \multirow[t]{2}{*}{35} & Prednisolone & Oral & $5 \mathrm{mg}$ & 10.03 & +++ \\
\hline & & & & 15.49 & +++ \\
\hline
\end{tabular}

GC, glucocorticoid; d, day; 5-mC, 5-methylcytosine; /, not measured; -, no intake or no expression; +, low expression; ++, moderate expression; +++, high expression.

TGF- $\beta 2$ protein in PANC-1 cells, as shown by western blot analysis (Fig. 3C). To evaluate clinical significance, expression of TGF- $\beta 2$ was examined in tissue samples from patients with PDA who had received inhaled $(n=8)$ or oral $(n=6)$ GCs prior to surgery, and in tissues from patients with PDA who had not received GCs $(n=20)$. With the use of a semi-quantitative scoring system, we detected higher expression of TGF- $\beta 2$ in the tissues of patients who had received GCs compared with tissues from those who had not. There was a slight though insignificant increase in expression in tissues from those who had received oral GCs compared with those who had received inhaled GCs (Fig. 3D; Table II). We also assessed the expression of miR-132 in patient tissues by in situ hybridization. Although expression of miR-132 was detectable in both groups (Fig. 3E), 

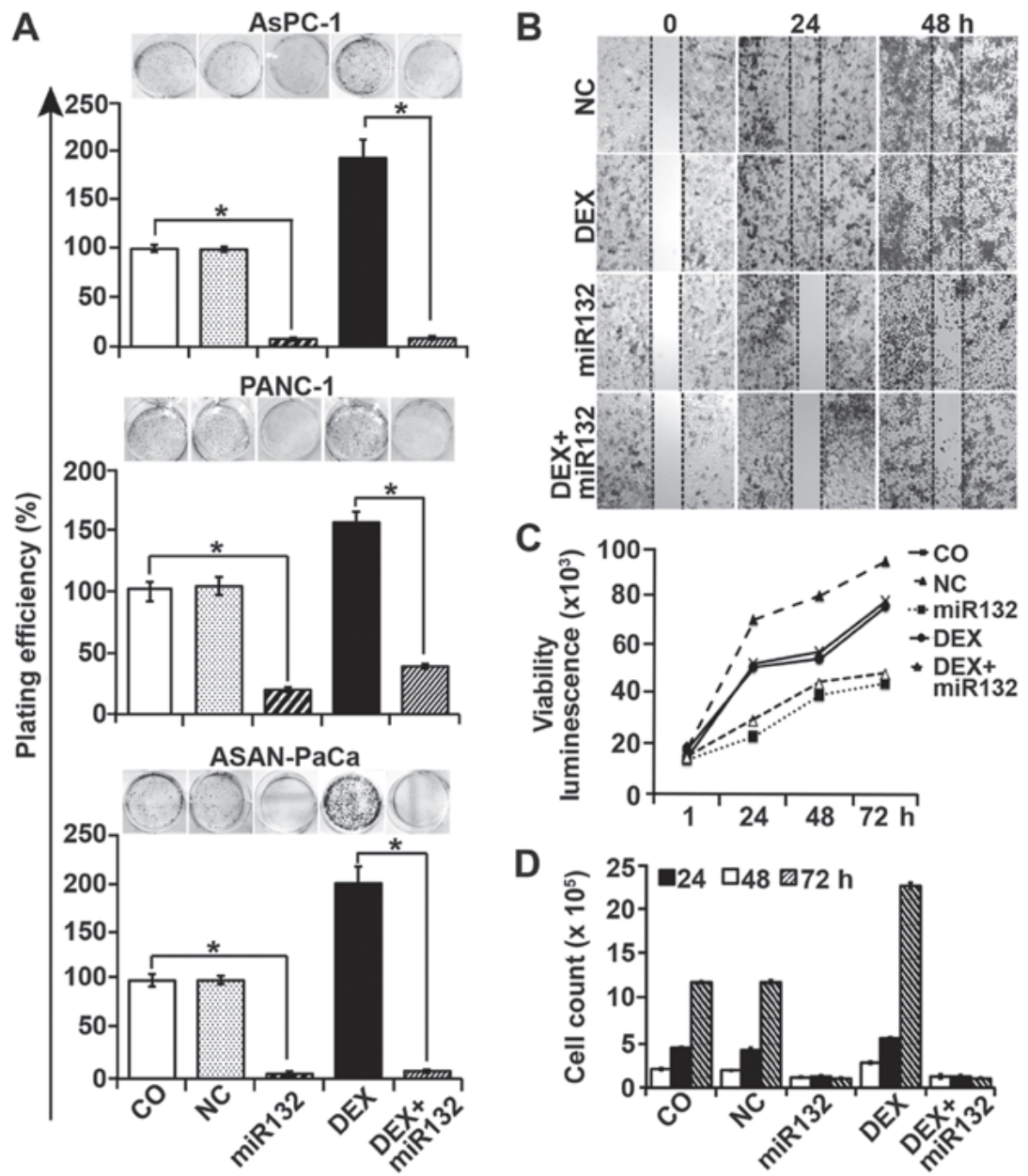

Figure 4. Cancer progression features are inhibited by miR-132. (A) AsPC-1, PANC-1 and ASAN-PaCa cells were transfected with $50 \mathrm{nM}$ miR-132 mimics or a negative miR control (NC). At $8 \mathrm{~h}$ later, the cells were treated with $1 \mu \mathrm{M} \mathrm{DEX}$ in the presence or absence of miR-132. After $48 \mathrm{~h}$, the cells were resuspended in complete medium and plated at a low clonogenic density in 6-well tissue culture plates. After 14 days, colony-forming assays were performed and evaluated as described in the materials and methods. (B) PANC-1 cells were transfected as aforementioned. At $48 \mathrm{~h}$ after transfection, the cells were seeded at a high density in ibidi culture insert 24-well plates. After $24 \mathrm{~h}$, once the cells had attached and reached $\sim 90 \%$ confluency, the inserts were removed to leave a defined $500-\mu \mathrm{m}$-thick scratch. Images of the cell-free gap were obtained immediately $(0 \mathrm{~h})$, and at 24 and $48 \mathrm{~h}$ after removal of the inserts. (C) PANC-1 cells were treated as afore-described, and cell viability was measured using a RealTime-Glo ${ }^{\mathrm{TM}}$ MT Cell Viability Assay. (D) The number of PANC-1 cells was determined by the use of a Coulter counter after 24,48 and $72 \mathrm{~h}$ of treatment. Data are presented as the means $\pm \mathrm{SD}$. ${ }^{*} \mathrm{P}<0.05$. DEX, dexamethasone; NC, negative miR control.

we were unable to perform a quantitative analysis. Due to a lack of suitable patient tissue, we could not evaluate miR-132 expression by RT-qPCR. Nevertheless, expression of miR-132 and TGF- $\beta 2$ in patient tissue underlines the potential clinical significance of our in vitro data.

miR-132 reverses $D E X$-induced clonogenicity, migration and proliferation. To examine the role of miR-132 and its target gene TGF- $\beta 2$ in DEX-induced EMT and CSC signaling, we performed colony-forming assays, which allowed us to evaluate the influence of miR-132 on clonogenicity as a typical stem cell feature. Cells were transfected with miR-132 mimics or non-coding control mimics, and then either treated with DEX $8 \mathrm{~h}$ later or left untreated. At $48 \mathrm{~h}$ after DEX treatment, the cells were seeded at a clonogenic concentration, followed by evaluation of colony formation 14 days later. Untreated control cells and cells treated with control mimics formed colonies, and DEX enhanced the colony number. However, miR-132 mimics strongly inhibited both basal and DEX-induced colony formation (Fig. 4A). Similar results were obtained in wound-healing assays, wherein miR-132 completely inhibited basal and DEX-induced PANC-1 cell migration into the wounded region (Fig. 4B). Similarly, miR-132 attenuated basal and DEX-enhanced cell viability and cell number, as measured by a luminescence-based viability assay (Fig. 4C) and the quantification of cell numbers with a Coulter counter (Fig. 4D), respectively.

These results were also reflected by the expression patterns of EMT markers, as assessed by RT-qPCR. miR-132 mimics significantly inhibited DEX-induced expression of the mesenchymal marker vimentin and significantly activated basal and DEX-inhibited expression of the epithelial marker E-cadherin (Fig. 5A). By contrast, transfection with antisense mimics targeting miR-132 upregulated E-cadherin and downregulated vimentin expression, regardless of the presence of DEX. These results were confirmed by western blot analysis (Fig. 5B).

miR-132 inhibits tumor growth in vivo. For in vivo evaluation, we used the CAM xenotransplantation model. Prior to xenotransplantation, ASAN-PaCa cells were transfected with miR-132 or negative control mimics, followed by the application of DEX $24 \mathrm{~h}$ later, which was added to both untreated and miR-132-transfected cells. At $48 \mathrm{~h}$ post-transfection, $5 \times 10^{5}$ 
A

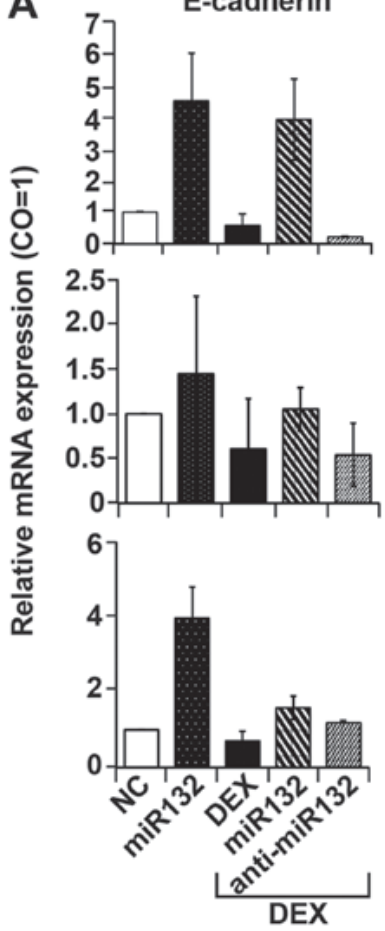

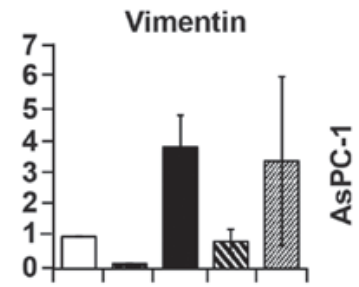
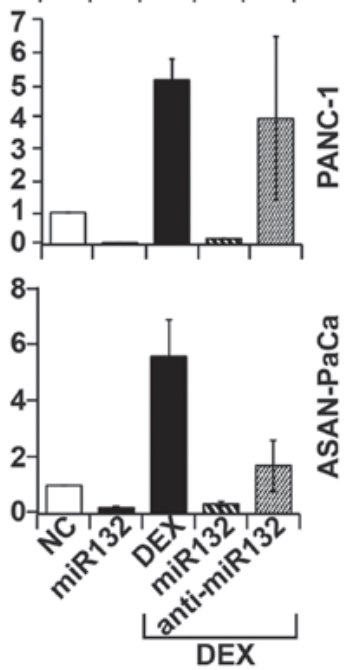

B

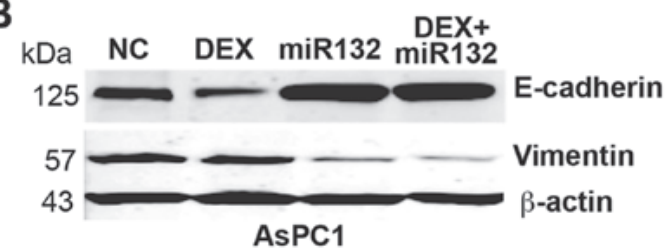

Figure 5. Overexpression of miR-132 reverses EMT. (A) AsPC-1, PANC-1 and ASAN-PaCa cells were transfected with $50 \mathrm{nM}$ miR-132 mimics, anti-miR-132 or negative miR control (NC) or were treated with $1 \mu \mathrm{M}$ DEX in parallel or at $8 \mathrm{~h}$ after transfection in the presence or absence of miR-132 or anti-miR-132. At 48 h later, expression of E-cadherin and vimentin was examined via TaqMan miR real-time qPCR, as described in Fig. 2D. (B) AsPC-1 cells were transfected and treated with DEX as aforementioned, followed by protein isolation and western blot analysis using antibodies specific for E-cadherin and vimentin. $\beta$-actin was used as an internal control. The results for part A are shown as means. EMT, epithelial mesenchymal transition; miR, microRNA.

cells per egg were transplanted onto the CAM at day 8 of chick development ( $\mathrm{n}=25$ eggs per group). On day 14 of embryonic development, $50 \mathrm{nM}$ miR-132 mimics, negative control mimics, DEX in saline or saline alone was injected into the CAM vessels supplying the tumor xenografts. On day 18, the chick embryos were humanely euthanized, followed by resection of the tumor xenografts and determination of their volume by calipers. Large tumor xenografts developed in the groups treated with the negative control mimics or DEX alone, whereas the tumor sizes in the miR-132 groups were significantly smaller (Fig. 6A). Notably, the mean weight of the chick embryos in the DEX-treated group was $\sim 10 \mathrm{~g}$ and thus one-third lower than that of the control embryos (15 g) (Fig. 6B). This change in embryo weight suggests that DEX interferes with embryonic development, as already shown in humans (34). It may be assumed that the tumor volumes of the DEX-treated group would have been much higher when relative to a normal body weight. However, in vivo treatment with miR-132 normalized the body weight despite

the presence of DEX. To highlight these results, we examined the xenograft sections by IHC. DEX treatment was associated with increased proliferation, as indicated by Ki-67 expression and enhanced TGF- $\beta 2$ expression (Fig. 6C). Both the basal and DEX-induced expression patterns of Ki-67 and TGF- $\beta 2$ were strongly suppressed in the presence of miR-132. Similarly, the low expression of E-cadherin was restored in the presence of miR-132, and the high expression of vimentin was inhibited. Nonetheless, the effect of DEX on the basal expression levels of E-cadherin and vimentin was difficult to quantify in vivo.

\section{Discussion}

The present study is based on our recent finding that DEX meditates PDA progression through its actions on the GC receptor, TGF- $\beta$ and JNK/AP1 (4) Here, we evaluate the mechanism underlying DEX-induced upregulation of TGF- $\beta$. Because a number of studies have suggested that miRNAs are important mediators of GC signaling $(35,36)$, we performed miRNA microarray analysis and identified several significantly DEX-deregulated miRNAs, with miR-132 as the top downregulated candidate. Through in silico analysis and luciferase reporter assays, we identified TGF- $\beta 2$ as a target gene and demonstrated the direct binding of miR-132 to the TGF- $\beta 2$ 3'UTR region, which was responsible for the observed inhibition of TGF- $\beta 2$ expression. Consequently, inhibition of miR-132 by DEX led to the upregulation of TGF- $\beta 2$ expression. This DEX-induced regulation of TGF- $\beta 2$ is an important finding because TGF- $\beta 2$ is a main component of the TGF- $\beta$ signaling cascade and mediator of EMT and cancer progression $(37,38)$.

In general, TGF- $\beta$ acts as a tumor suppressor in normal and pre-malignant cells; during progression, however, cancer cells lose the suppressive effect of TGF- $\beta$, which then increases expression of growth factors and thereby promotes differentiation, invasion and metastasis $(37,39)$. We presume that dysregulation of miR-132 and its target gene TGF- $\beta$ might begin early in cancer development with the upregulation of miR-132-3p and downregulation of TGF, based on our RT-qPCR results after $0.5 \mathrm{~h}$ of DEX treatment. miR-132-3p might be gradually downregulated during cancer progression until its complete inhibition in the advanced stages, as suggested by our RT-qPCR results after 24 and $96 \mathrm{~h}$ of DEX treatment. This conclusion is underlined by our observation that miR-132 overexpression led to strong inhibition of DEX-induced clonogenicity, migration, and proliferation as well as modulation of E-cadherin and vimentin expression patterns. These in vitro data were confirmed in vivo, whereby overexpression of miR-132 inhibited tumor xenograft growth and normalized expression of TGF- $\beta 2$, vimentin, and E-cadherin. Most importantly, miR-132 abolished the observed DEX-induced reduction in chick embryo weight and body size. Birth weight reduction caused by administration of synthetic GCs during pregnancy to improve fetal lung maturity in threatened preterm birth is a well-known problem (40), which may be overcome by co-application with miR-132 as a future treatment option.

Although GC-induced miRNA signaling in PDA has not been well studied to date, the idea that miRNA signaling may be regulated by GCs is not new. For example, Zhao et al (35) demonstrated the importance of the miR-221-222 family in DEX-induced drug resistance in multiple myeloma, 
A

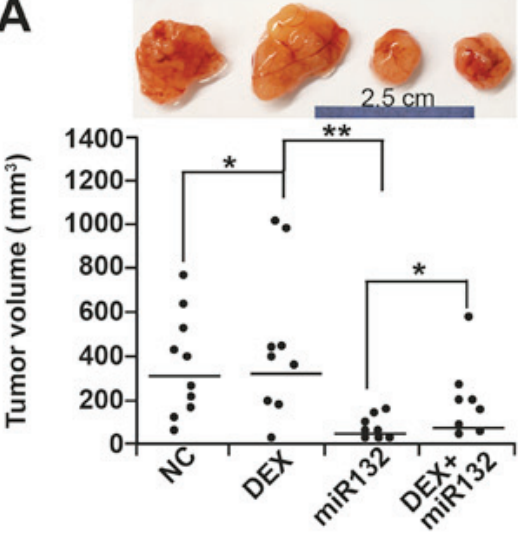

C

DEX

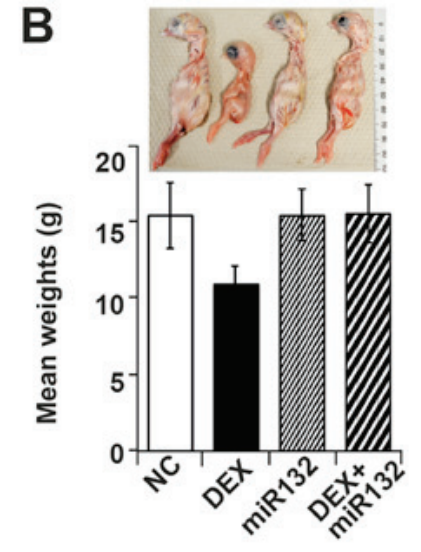

$\operatorname{miR} 132$

DEX+

miR132
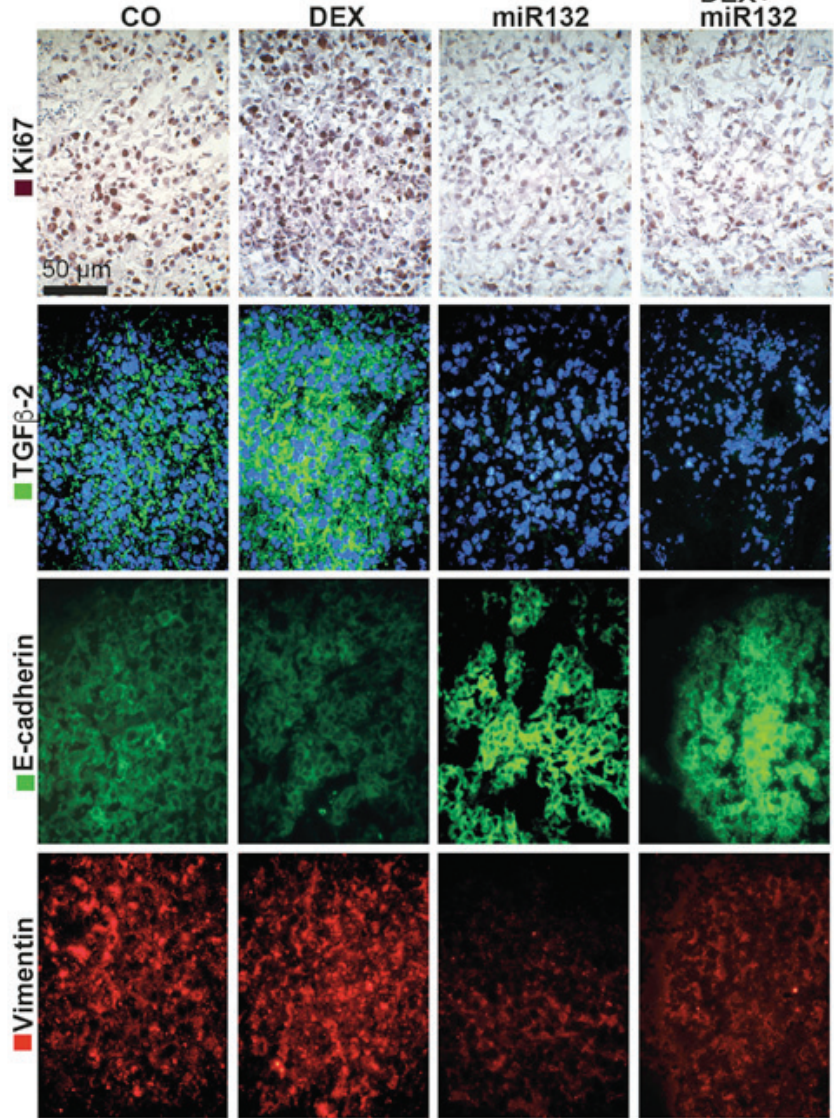

Figure 6. miR-132 suppresses cancer features in vivo. (A) ASAN-PaCa cells were treated as described in Fig. $4 \mathrm{~A}$. At $48 \mathrm{~h}$ later, $5 \mathrm{x} 10^{5}$ viable cells were transplanted to the CAM of fertilized chicken eggs at day 8 of embryonic development. After 10 days, the tumors were resected, and the volumes were determined using calipers; the results are presented as single dots in the diagram. The means of each group are presented as a line. Representative images of xenografts are shown above the diagrams; ${ }^{*} \mathrm{P}<0.05$ and ${ }^{* *} \mathrm{P}<0.01$. (B) Representative images of the chicks from each group and the mean weights are shown. (C) IHC staining of the human proliferation marker Ki-67 in frozen xenograft sections. Positive cells appear red-dark red. Similarly, expression of TGF- $\beta 2$ (green), E-cadherin (green), and vimentin (red) was detected by immunofluorescence staining and counterstaining of cell nuclei with DAPI (blue). Sections were analyzed under x400 magnification, and representative images are shown. CAM, chorioallantoismembrane; IHC, immunohistochemistry; TGF, transforming growth factor.

and $\mathrm{Kim}$ et al (36) reported that miR-124 is an attractive therapeutic target for overcoming GC resistance in lymphoma. Nevertheless, the effect of DEX on global miRNA expression and the phenotype resulting from this deregulation in PDA has never been evaluated, to the best of our knowledge. Thus, our study provides pioneer data. Our genome-wide microarray analysis of miRNA changes in response to DEX identified 268 significant candidates. The top deregulated miRNAs, including miR-210, miR-378i, miR-125a-5p, miR-132 and miR-1260b, have all been reported to have important roles in regulating such processes as cell growth, angiogenesis, migration, invasion, proliferation, and apoptosis in different human tumor models (41-45). Among the significant candidates identified, we validated miR-132-3p as the most significantly downregulated miRNA, because, according to bioinformatics target prediction algorithms, miR-132-3p is a target for key genes in important signaling pathways. This miRNA is produced from the miR-212/132 cluster, and miR-132-3p has been reported to be deregulated in several malignancies. Its function appears to be complicated: miR-132-3p has been described as oncogenic 
in pancreatic, breast, and colorectal cancers (46), but as tumor suppressive in osteosarcoma, prostate, non-small cell lung, and ovarian cancers (47). In PDA, overexpression of miR-132 has been suggested to play a role in tumor progression by targeting the patched 1 (PTCH1) receptor in the Hedgehog pathway (48). In accordance with our findings, Kawashima et al (49) previously showed that DEX inhibits miR-132 expression in the brain, which was considered to lead to the suppression of invasion and metastasis. In agreement with our results, Zheng et al (50) showed that miR-132 regulates EMT in colorectal cancer via direct binding to the 3'UTR region of ZEB2, a transcriptional suppressor of E-cadherin, which has a role in EMT.

Overall, only a limited number of studies have attempted to explain the mechanisms of miRNA differential regulation by GCs. In this regard, Smith et al (51) reported that Dicer repression in response to GCs was responsible for the reduced expression of certain miRNA candidates. We found a high-density $\mathrm{CpG}$ island in the miR-132 promoter region and observed a 2-fold global increase in DNA methylation in response to DEX, indicating the widespread silencing of several genes, as described previously (7). Specific analysis of the miR-132 promoter region revealed hypermethylation after DEX treatment; indeed, miR-132 expression was restored by a demethylating agent. Correspondingly, another study on prostate cancer showed that the miR-132 promoter is regulated by hypermethylation, which results in reduced expression (52).

In conclusion, the present study identified DEX-induced inhibition of miR-132 as a novel mediator of EMT and cancer progression in PDA, suggesting that the overexpression of miR-132 is a potential novel treatment option for basal and DEX-induced PDA progression.

\section{Acknowledgements}

We thank the microarray unit of the Genomics and Proteomics Core Facility of the German Cancer Research Center (DKFZ) Heidelberg for providing Illumina Whole-Genome Expression BeadChips and associated services. We are also grateful to Dr W. Gross for providing Histo 3.0 customized image analysis software and to Heiner Sähr, Jutta Mohr and Sebastian Faus for excellent technical assistance.

\section{Funding}

This study was supported by grants from the German Cancer Aid (grant no. Deutsche Krebshilfe 111299), the German Research Council (grant no. DFG HE 3186/15-1), the Federal Ministry of Education and Research (grant no. BMBF 031A213), the Heidelberger Stiftung Chirurgie, Dietmar Hopp-Stiftung, and the Hanns (A) Pielenz-Stiftung. The tissue bank of our clinic (PancoBank) was funded by the Heidelberger Stiftung Chirurgie, the Federal Ministry of Education and Research (grant no. BMBF 01GS08114) and the Biomaterial Bank Heidelberg/BMBH (grant no. BMBF 01EY1101).

\section{Consent for publication}

All authors agreed to submit this publication. This manuscript has not been published, and it is not under consideration for publication elsewhere.

\section{Availability of data and materials}

The datasets supporting the conclusions of this article are included within the article; data not shown are available from the corresponding author upon reasonable request.

\section{Authors' contributions}

IH, AA, OS: Concept and design. AA, CN, NB, ZZ, JF, JG: Development of the methodology. AA, JG: Acquisition of the data. AA, AB, WG, LL: Analysis and interpretation of the data. AA, IH: Writing, review and/or revision of the manuscript.

\section{Ethical approval and consent to participate}

Patient materials were obtained with the approval of the Ethical Committee of the University of Heidelberg after receiving written informed consent from each patient. Diagnoses were established according to conventional clinical and histological criteria set by the World Health Organization (WHO). All surgical resections were conducted as indicated by the principles and practice of oncological therapy.

\section{Patient consent for publication}

Not applicable.

\section{Competing interests}

The authors declare that they have no competing interests.

\section{References}

1. Siegel RL, Miller KD and Jemal A: Cancer Statistics, 2017. CA Cancer J Clin 67: 7-30, 2017.

2. Ryan DP, Hong TS and Bardeesy N: Pancreatic adenocarcinoma. N Engl J Med 371: 2140-2141, 2014.

3. Pufall MA: Glucocorticoids and cancer. Adv Exp Med Biol 872: 315-333, 2015.

4. Liu L, Aleksandrowicz E, Schönsiegel F, Gröner D, Bauer N, Nwaeburu CC, Zhao Z, Gladkich J, Hoppe-Tichy T, Yefenof E, et al: Dexamethasone mediates pancreatic cancer progression by glucocorticoid receptor, TGF $\beta$ and JNK/AP-1. Cell Death Dis 8: e3064, 2017.

5. Herr I and Pfitzenmaier J: Glucocorticoid use in prostate cancer and other solid tumours: Implications for effectiveness of cytotoxic treatment and metastases. Lancet Oncol 7: 425-430, 2006.

6. Volden PA and Conzen SD: The influence of glucocorticoid signaling on tumor progression. Brain Behav Immun 30 (Suppl): S26-S31, 2013.

7. Herr I, Ucur E, Herzer K, Okouoyo S, Ridder R, Krammer PH, von Knebel Doeberitz M and Debatin KM: Glucocorticoid cotreatment induces apoptosis resistance toward cancer therapy in carcinomas. Cancer Res 63: 3112-3120, 2003.

8. Puhr M, Hoefer J, Eigentler A, Ploner C, Handle F, Schaefer G Kroon J, Leo A, Heidegger I, Eder I, et al: The glucocorticoid receptor is a key player for prostate cancer cell survival and a target for improved antiandrogen Therapy. Clin Cancer Res 24: 927-938, 2018

9. Iversen HG and Hjort GH: The influence of corticoid steroids on the frequency of spleen metastases in patients with breast cancer. Acta Pathol Microbiol Scand 44: 205-212, 1958.

10. Sherlock P and Hartmann WH: Adrenal steroids and the pattern of metastases of breast cancer. JAMA 181: 313-317, 1962.

11. Melhem A, Yamada SD, Fleming GF, Delgado B, Brickley DR, Wu W, Kocherginsky M and Conzen SD: Administration of glucocorticoids to ovarian cancer patients is associated with expression of the anti-apoptotic genes SGK1 and MKP1/DUSP1 in ovarian tissues. Clin Cancer Res 15: 3196-3204, 2009. 
12. Pan D, Kocherginsky M and Conzen SD: Activation of the glucocorticoid receptor is associated with poor prognosis in estrogen receptor-negative breast cancer. Cancer Res 71: 6360-6370, 2011.

13. Wong ET, Lok E, Gautam S and Swanson KD: Dexamethasone exerts profound immunologic interference on treatment efficacy for recurrent glioblastoma. Br J Cancer 113: 1642, 2015.

14. Hirai H, Tomioka H, Mochizuki Y, Oikawa Y, Tsushima F and Harada H: Clinical course of oral squamous cell carcinoma in patients on immunosuppressant and glucocorticoid therapy. J Oral Maxillofac Surg 75: 1980-1986, 2017.

15. Wang HY, Chang YL, Cheng CC, Chao MW, Lin SI, Pan SL, Hsu CC, Liu TW, Cheng HC, Tseng CP, et al: Glucocorticoids may compromise the effect of gefitinib in non-small cell lung cancer. Oncotarget 7: 85917-85928, 2016.

16. Sørensen HT, Mellemkjaer L, Nielsen GL, Baron JA, Olsen JH and Karagas MR: Skin cancers and non-hodgkin lymphoma among users of systemic glucocorticoids: A population-based cohort study. J Natl Cancer Inst 96: 709-711, 2004.

17. Dietrich K, Schned A, Fortuny J, Heaney J, Marsit C, Kelsey KT and Karagas MR: Glucocorticoid therapy and risk of bladder cancer. Br J Cancer 101: 1316-1320, 2009.

18. Ha M and Kim VN: Regulation of microRNA biogenesis. Nat Rev Mol Cell Biol 15: 509-524, 2014.

19. Calin GA and Croce CM: MicroRNA signatures in human cancers. Nat Rev Cancer 6: 857-866, 2006.

20. Zhu M, Xu Z, Wang K, Wang N and Li Y: microRNA and gene networks in human pancreatic cancer. Oncol Lett 6: 1133-1139, 2013.

21. Shi M, Du L, Liu D, Qian L, Hu M, Yu M, Yang Z, Zhao M Chen C, Guo L, et al: Glucocorticoid regulation of a novel HPV-E6-p53-miR-145 pathway modulates invasion and therapy resistance of cervical cancer cells. J Pathol 228: 148-157, 2012.

22. Heller A, Angelova AL, Bauer S, Grekova SP, Aprahamian M, Rommelaere J, Volkmar M, Janssen JW, Bauer N, Herr I, et al: Establishment and characterization of a novel cell line, ASAN$\mathrm{PaCa}$, derived from human adenocarcinoma arising in intraductal papillary mucinous neoplasm of the pancreas. Pancreas 45: 14521460,2016

23. Zhang S, Hao J, Xie F, Hu X, Liu C, Tong J, Zhou J, Wu J and Shao C: Downregulation of miR-132 by promoter methylation contributes to pancreatic cancer development. Carcinogenesis 32: 1183-1189, 2011

24. Betel D, Wilson M, Gabow A, Marks DS and Sander C: The microRNA.org resource: Targets and expression. Nucleic Acids Res 36: D149-D153, 2008.

25. Lewis BP, Burge CB and Bartel DP: Conserved seed pairing, often flanked by adenosines, indicates that thousands of human genes are microRNA targets. Cell 120: 15-20, 2005.

26. Dweep H, Sticht C, Pandey P and Gretz N: miRWalk - database: Prediction of possible miRNA binding sites by 'walking' the genes of three genomes. J Biomed Inform 44: 839-847, 2011.

27. Krek A, Grün D, Poy MN, Wolf R, Rosenberg L, Epstein EJ MacMenamin P, da Piedade I, Gunsalus KC, Stoffel M, et al: Combinatorial microRNA target predictions. Nat Genet 37: 495-500, 2005

28. Livak KJ and Schmittgen TD: Analysis of relative gene expression data using real-time quantitative PCR and the 2(-Delta Delta C(T)) method. Methods 25: 402-408, 2001.

29. Herman JG, Graff JR, Myöhänen S, Nelkin BD and Baylin SB Methylation-specific PCR: A novel PCR assay for methylation status of CpG islands. Proc Natl Acad Sci USA 93: 9821-9826, 1996.

30. Kallifatidis G, Rausch V, Baumann B, Apel A, Beckermann BM, Groth A, Mattern J, Li Z, Kolb A, Moldenhauer G, et al: Sulforaphane targets pancreatic tumour-initiating cells by NF-kappaB-induced antiapoptotic signalling. Gut 58: 949-963, 2009.

31. Zhang Y, Liu L, Fan P, Bauer N, Gladkich J, Ryschich E, Bazhin AV, Giese NA, Strobel O, Hackert T, et al: Aspirin counteracts cancer stem cell features, desmoplasia and gemcitabine resistance in pancreatic cancer. Oncotarget 6: 9999-10015, 2015.

32. Jørgensen S, Baker A, Møller S and Nielsen BS: Robust one-day in situ hybridization protocol for detection of microRNAs in paraffin samples using LNA probes. Methods 52: 375-381, 2010.

33. Amponsah PS, Fan P, Bauer N, Zhao Z, Gladkich J, Fellenberg J and Herr I: microRNA-210 overexpression inhibits tumor growth and potentially reverses gemcitabine resistance in pancreatic cancer. Cancer Lett 388: 107-117, 2017.
34. Fan P, Zhang Y, Liu L, Zhao Z, Yin Y, Xiao X, Bauer N, Gladkich J, Mattern J, Gao C, et al: Continuous exposure of pancreatic cancer cells to dietary bioactive agents does not induce drug resistance unlike chemotherapy. Cell Death Dis 7: e2246, 2016.

35. Zhao JJ, Chu ZB, Hu Y, Lin J, Wang Z, Jiang M, Chen M, Wang X, Kang Y, Zhou Y, et al: Targeting the miR-221-222/ PUMA/BAK/BAX pathway abrogates dexamethasone resistance in multiple myeloma. Cancer Res 75: 4384-4397, 2015.

36. Kim J, Jeong D, Nam J, Aung TN, Gim JA, Park KU and Kim SW: MicroRNA-124 regulates glucocorticoid sensitivity by targeting phosphodiesterase 4B in diffuse large B cell lymphoma. Gene 558: 173-180, 2015.

37. Butz H, Rácz K, Hunyady L and Patócs A: Crosstalk between TGF- $\beta$ signaling and the microRNA machinery. Trends Pharmacol Sci 33: 382-393, 2012.

38. Zaravinos A: The Regulatory Role of MicroRNAs in EMT and Cancer. J Oncol 2015: 865816, 2015.

39. Brabletz T: EMT and MET in metastasis: Where are the cancer stem cells? Cancer Cell 22: 699-701, 2012.

40. Painter RC, Roseboom TJ and de Rooij SR: Long-term effects of prenatal stress and glucocorticoid exposure. Birth Defects Res C Embryo Today 96: 315-324, 2012.

41. Tang L, Shen H, Li X, Li Z, Liu Z, Xu J, Ma S, Zhao X, Bai X, Li M, et al: MiR-125a-5p decreases after long non-coding RNA HOTAIR knockdown to promote cancer cell apoptosis by releasing caspase 2. Cell Death Dis 7: e2137, 2016.

42. Hong L, Han Y, Zhang H, Zhao Q and Qiao Y: miR-210: A therapeutic target in cancer. Expert Opin Ther Targets 17: 21-28, 2013.

43. Chen QG, Zhou W, Han T, Du SQ, Li ZH, Zhang Z, Shan GY and Kong CZ: MiR-378 suppresses prostate cancer cell growth through downregulation of MAPK1 in vitro and in vivo. Tumour Biol 37: 2095-2103, 2016.

44. Li S, Meng H, Zhou F, Zhai L, Zhang L, Gu F, Fan Y, Lang R, $\mathrm{Fu} \mathrm{L}, \mathrm{Gu} \mathrm{L}$, et al: MicroRNA-132 is frequently down-regulated in ductal carcinoma in situ (DCIS) of breast and acts as a tumor suppressor by inhibiting cell proliferation. Pathol Res Pract 209: 179-183, 2013.

45. Hirata H,Hinoda Y, Shahryari V, Deng G, Tanaka Y, Tabatabai ZL and Dahiya R: Genistein downregulates onco-miR-1260b and upregulates sFRP1 and Smad4 via demethylation and histone modification in prostate cancer cells. Br J Cancer 110: 1645-1654, 2014.

46. Formosa A, Lena AM, Markert EK, Cortelli S, Miano R, Mauriello A, Croce N, Vandesompele J, Mestdagh P, Finazzi-Agrò E, et al: DNA methylation silences miR-132 in prostate cancer. Oncogene 32: 127-134, 2013.

47. Fu W, Tao T, Qi M, Wang L, Hu J, Li X, Xing N, Du R and Han B: MicroRNA-132/212 upregulation inhibits TGF- $\beta$-mediated epithelial-mesenchymal transition of prostate cancer cells by targeting SOX4. Prostate 76: 1560-1570, 2016.

48. Ma C, Nong K, Wu B, Dong B, Bai Y, Zhu H, Wang W, Huang $X$, Yuan $Z$ and Ai K: miR-212 promotes pancreatic cancer cell growth and invasion by targeting the hedgehog signaling pathway receptor patched-1. J Exp Clin Cancer Res 33: 54, 2014.

49. Kawashima H, Numakawa T, Kumamaru E, Adachi N, Mizuno H, Ninomiya M, Kunugi H and Hashido K: Glucocorticoid attenuates brain-derived neurotrophic factor-dependent upregulation of glutamate receptors via the suppression of microRNA-132 expression. Neuroscience 165: 1301-1311, 2010.

50. Zheng YB, Luo HP, Shi Q, Hao ZN, Ding Y, Wang QS, Li SB, Xiao GC and Tong SL: miR-132 inhibits colorectal cancer invasion and metastasis via directly targeting ZEB2. World J Gastroenterol 20: 6515-6522, 2014

51. Smith LK, Shah RR and Cidlowski JA: Glucocorticoids modulate microRNA expression and processing during lymphocyte apoptosis. J Biol Chem 285: 36698-36708, 2010.

52. Qin J, Ke J, Xu J, Wang F, Zhou Y, Jiang Y and Wang Z: Downregulation of microRNA-132 by DNA hypermethylation is associated with cell invasion in colorectal cancer. Onco Targets Ther 8: 3639-3648, 2015.

This work is licensed under a Creative Commons Attribution-NonCommercial-NoDerivatives 4.0 International (CC BY-NC-ND 4.0) License. 